(2) OPEN ACCESS

\title{
Occupational factors in the COVID-19 pandemic in Italy: compensation claims applications support establishing an occupational surveillance system
}

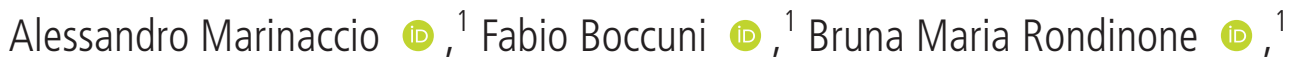 \\ Adelina Brusco, ${ }^{2}$ Silvia D'Amario, ${ }^{2}$ Sergio lavicoli (i) ${ }^{1}$
}

'Department of Medicine, Epidemiology, Workplace and Environmental Hygiene, INAIL, Roma, Lazio, Italy ${ }^{2}$ Statistical Actuarial Office, INAIL, Roma, Lazio, Italy

\section{Correspondence to} Dr Alessandro Marinaccio, Department of Medicine, Epidemiology, Workplace and Environmental Hygiene Roma, INAIL, Roma 00143, Lazio, Italy; a.marinaccio@inail.it

Received 26 June 2020 Revised 28 August 2020 Accepted 2 September 2020 Published Online First 23 September 2020

\section{ABSTRACT}

Introduction The SARS-CoV-2 pandemic is

an impacting challenge for occupational health. Epidemiological surveillance of COVID-19 includes systematic tracking and reporting of the total cases and deaths, but suitable experiences of surveillance systems for identifying the occupational risk factors involved in the COVID-19 pandemic are still missing, despite the interest for occupational safety and health.

Methods A methodological approach has been implemented in Italy to estimate the occupational risk of infection, classifying each economic sector as at low, medium-low, medium-high and high risk, based on three parameters: exposure probability, proximity index and aggregation factor. Furthermore, during the epidemic emergency, the Italian Workers' Compensation Authority introduced the notation of COVID-19 workrelated infection as an occupational injury and collected compensation claims of workers from the entire national territory.

Results According to compensation claims applications, COVID-19 infection in Italy has been acquired at the workplace in a substantial portion of the total cases (19.4\%). The distribution of the economic sectors involved is coherent with the activities classified at risk in the lockdown period. The economic sectors mostly involved were human health and social work activities, but occupational compensation claims also include cases in meat and poultry processing plants workers, store clerks, postal workers, pharmacists and cleaning workers. Conclusions There is a need to go towards an occupational surveillance system for COVID-19 cases, including an individual anamnestic analysis of the circumstances in which the infection is acquired, for the prevention of occupational infectious risk, supporting insurance system effectiveness and managing vaccination policies.

\section{INTRODUCTION}

It was repeatedly underlined that SARS-CoV-2 pandemic is an impacting challenge for occupational health ${ }^{1}$ and several working conditions have been considered as at risk of infection worldwide. Nevertheless, the contribution of work-related factors to the epidemic is less known, and suitable experiences of surveillance systems for identifying the occupational risk factors involved in the COVID-19 pandemic are still missing. ${ }^{2}$ Recently, WHO has distributed a minimum data set for surveillance of

\section{Key messages}

What is already known about this subject?

- Coronavirus infection 2019 is a great challenge for occupation health and safety. Clusters of occupationally exposed subjects have been reported worldwide.

\section{What are the new findings?}

- According to compensation claims, in Italy, SARS-CoV-2 infection has been acquired at the workplace in a substantial portion of the total cases $(19.4 \%)$. The distribution of the economic sectors involved is coherent with the activities classified at risk in the lockdown period.

How might this impact on policy or clinical practice in the foreseeable future?

- There is a need to go towards an occupational surveillance system for COVID-19 infection, with the aim of monitoring and preventing the occupational risk of infection, supporting insurance system effectiveness and managing vaccination policies.

the disease, including a question about healthcare workers (any job in the healthcare sector), but no information to identify other work related risks has been considered. ${ }^{3}$ Occupational and compensation data are useful to plan prevention policies, to identify vulnerable groups, to define the priorities in vaccination strategies and to use the public resources of insurance systems correctly.

Italy is one of the countries most affected by the COVID-19 pandemic: at the date of the present work, more than 245000 cases of COVID-19 and 35000 associated deaths have been recognised with the highest peak of more than 6500 new confirmed cases on 22 March, and a regular decrease of the epidemic curve still ongoing. Data on occupational infections are available only for health workers reporting an infection rate equal to $12.2 \%$ of the total cases, with many fatalities. ${ }^{4}$

To face the pandemic outbreak, the Italian government implemented a range of public health and social measures including the suspension of many non-essential work activities. During the lockdown phase, from 25 March to 4 May 2020, about 7.8 million workers $(33.3 \%$ of the total 
workforce) employed in non-essential businesses discontinued their professional activities, while the extensive implementation of smart working and annual leave further reduced the proportion of workers present in their workplace. ${ }^{56}$

In this context, this study aims to (i) describe insurance claims for compensation data for COVID-19 in Italy and the distribution of the economic sectors involved and (ii) compare the occupational data with the 'a priori' classification of occupational risk of infection by economic sector defined during the lockdown period.

\section{METHODS}

In the framework of the institutional measures to contrast the pandemic, a methodological approach has been implemented to estimate the risk for each economic sector in Italy, with different levels of detail and considering the impact on mobility of the working population in the postlockdown phase. It was adopted by the national Scientific Committee set up by the Italian government for action-oriented policy advice on the COVID-19 emergency. The average risk class of each economic sector, according to the ATECO national classification (Attivita' Economiche -in Italian, the equivalent of European Classification of Economic Activities-NACE) ${ }^{7}$ has been identified with the aim to plan and track the progressive lifting of the containment measures.

All economic sectors have been classified as at low, medium-low, medium-high and high risk, based on three parameters: exposure probability, proximity index and aggregation factor. The first two parameters measure the probability, due to the work activity, to be in contact with infected people and the physical proximity to others during work activities by the adaptation of proximity and exposure perception indicators defined by $\mathrm{O}^{*} \mathrm{Net}^{8}$ methodology to the Italian context. Meanwhile, the aggregation factor quantifies the social aggregation connected to the job, rating from the scant presence of third parties to large aggregations not easily controlled by specific procedures. ${ }^{5}$

At the same time, the Italian Workers' Compensation Authority (INAIL) systematically receives claims for occupational injuries over the whole national territory for providing wage replacement, regarding all workers, except for some categories (armed forces, firefighters and police workers, air transport personnel, tradespeople and freelance workers), for which specific insurance systems are in place. The coverage level of the public insurance system leaded by INAIL is about $85 \%$ of the national workforce. During the epidemic emergency, INAIL introduced the notation of COVID-19 work related infection as an occupational injury. We have analysed only compensation claims (applications), without considering their possible acceptance. A comparative analysis between the economic sectors most involved in the risk of infection and the insurance figures has been performed estimating the percentage of compensation claims by the second digit of the ATECO national classification for each average risk class.

\section{RESULTS}

As of 15 May 2020, the Italian national data reported 223885 total cases (with 31610 deaths) of infected subjects; on the same date, 43399 COVID-19 occupationally infected cases were registered by INAIL (19.4\% of total subjects and approximatively $30 \%$ of subjects in working age), with a median age at diagnosis equal to 47 years in both genders. The economic sector of exposure was reported for 29320 compensation claims applications (67.6\%). The distribution of these sectors is reported in table 1 (at the first digit of the ATECO classification), which includes also the estimated risk class, the numbers of working population and active workers during the national lockdown phase, calculated using ISTAT surveys. ${ }^{6}$ According to the proposed risk classification, 'Human health and social work activities' sector resulted at higher average risk; 'Activities of households...' and 'Public administration and defence...' at medium-high risk; 'Education', 'Arts, entertainment and recreation' and 'Other services' at medium-low risk, while for all further sectors the average risk was classified as low. As a result, the economic sectors at high or medium-high risk of COVID-19 infection include $82 \%$ of compensation claims, although they represent about $25 \%$ of those workers who remained active during the lockdown period. The analyses at the second digit of the ATECO classification allowed to further specify the risk class of work activities included in each economic sector, marking pharmacists, professional athletes, beauticians and hairstylists as involved categories. Considering the second digit, the level of concordance remained high (50.6\% of compensation claims in high-risk sectors, $31.4 \%$ in $\mathrm{MH}, 5.6 \%$ in $\mathrm{ML}, 12.4 \%$ in $\mathrm{L}$ ). Furthermore, occupational compensation claims include cases in meat and poultry processing plants workers in Southern Italy, store clerks, postal workers and cleaning workers.

\section{DISCUSSION}

Occupational risk of SARS-CoV-2 infection is a real concern, but despite the interest from policy makers and in planning adequate prevention measures, a systematic surveillance of work-related risk factors is still missing.

Using compensation claims applications in Italy, this study provides evidence that the COVID-19 infection has acquired at the workplace in a substantial portion of the total cases (19.4\%). Furthermore, the distribution by economic sectors of cases with occupational origin appears coherent with the activities classified at risk in the lockdown period. The public health utility of these findings concerns the help in monitoring and preventing the occupational risk of infection, supporting insurance system effectiveness and managing vaccination policies. The unique data available at national level on occupational infections related to health workers are in line with the reported compensation claims in this sector, which has been classified at high risk. Some clusters of other occupationally exposed categories have been reported worldwide. Outbreaks of the virus have been reported in meat and poultry processing factories in the USA ${ }^{9}$ and in other countries. Cases of COVID-19 have been observed in other congregate settings, including correctional facilities ${ }^{10}$ and homeless shelters. ${ }^{11}$ Data on the occupational fraction of COVID-19 are seldom available in literature and there is a need to go towards an occupational surveillance system including individual anamnesis for patients with COVID-19.

The main strength of this study is the use of compensation claims obtained by the systematic collection of data by INAIL over the whole national territory, with standard criteria for diagnosis and classification of the economic sector of activities. At the same time, INAIL compensation claim data could present a relevant degree of underreporting, which is difficult to estimate owing to the scarcity of alternative sources of information. Furthermore, at the opposite, this study may have overestimated risk because compensation claims applications and not accepted claims were analysed and the statistical analyses of acceptance rates require a sufficient period for the administrative and insurance evaluation.

The compensation claims show that a substantial number (approximatively $30 \%$ of all cases in working age) were reported as work 
Table 1 Number of employed, active workers in the lockdown phase, risk class of SARS-CoV-2 infection and compensation claims applications by economic sector in Italy

\begin{tabular}{|c|c|c|c|c|c|}
\hline Code & Economic sector (first digit ATECO classification) & $\begin{array}{l}\text { Employed } \\
\text { (thousands) }\end{array}$ & $\begin{array}{l}\text { Active workers } \\
\text { during the lockdown } \\
\text { (thousands) }\end{array}$ & $\begin{array}{l}\text { Average risk } \\
\text { class }\end{array}$ & $\begin{array}{l}\text { Compensation } \\
\text { claims applications } \\
\text { for COVID-19 (\%) }\end{array}$ \\
\hline A & Agriculture, forestry and fishing & 908.8 & 854.1 & L & 2.1 \\
\hline C & Manufacturing & 4321.4 & 1444.1 & $\mathrm{~L}$ & 2.6 \\
\hline D & Electricity, gas, steam and air conditioning supply & 114.1 & 114.1 & $\mathrm{~L}$ & 0.1 \\
\hline $\mathrm{E}$ & Water supply; sewerage, waste management and remediation activities & 242.8 & 242.8 & $\mathrm{~L}$ & 0.1 \\
\hline G & Wholesale and retail trade; repair of motor vehicles and motorcycles & 3286.5 & 1804.1 & $\mathrm{~L}$ & 1.1 \\
\hline H & Transportation and storage & 1142.7 & 1142.7 & L & 1.1 \\
\hline 1 & Accommodation and food service activities & 1480.2 & 317.6 & $\mathrm{~L}$ & 2.4 \\
\hline J & Information and communication & 618.1 & 618.1 & $\mathrm{~L}$ & 0.2 \\
\hline K & Financial and insurance activities & 635.6 & 635.6 & L & 0.2 \\
\hline $\mathrm{L}$ & Real estate activities & 164.0 & 0.0 * & $\mathrm{L}$ & 0.4 \\
\hline$P$ & Education & 1589.5 & 1589.5 & ML & 0.6 \\
\hline Q & Human health and social work activities & 1922.3 & 1922.3 & H & 71.6 \\
\hline R & Arts, entertainment and recreation & 318.2 & $0.0^{*}$ & ML & 0.3 \\
\hline $\mathrm{S}$ & Other service activities & 711.6 & 280.8 & ML & 1.4 \\
\hline $\mathrm{T}$ & $\begin{array}{l}\text { Activities of households as employers; undifferentiated goods and services- } \\
\text { producing activities of households for own use }\end{array}$ & 738.9 & 733.3 & $\mathrm{MH}$ & 0.0 \\
\hline \multirow[t]{2}{*}{ U } & Activities of extraterritorial organisations and bodies & 14.1 & $0.0^{*}$ & $\mathrm{~L}$ & 0.0 \\
\hline & Total & 23359.9 & 15576.3 & & $29320(100 \%)$ \\
\hline
\end{tabular}

Sources: Employed and active workers during the lockdown period data have been retrieved by Istat (Italian Institute of Statistics); average risk class by economic sectors (Italian Scientific Committee) as stated in Methods section; compensation claims by Inail (Italian Workers Compensation Authority).

${ }^{*}$ Economic activity in this sector was completely suspended during the pandemic lockdown.

H, high; L, low; MH, medium-high; ML, medium-low.

related, supporting the notation of COVID-19 infection as an occupational disease in a consistent portion of cases. Consequently, it will be important to implement a control system also taking into account the occupational dimension as a substantial factor. Risk management strategies, prevention of the emergence of new epidemic clusters by strengthening the testing strategies, effective contact tracing, territorial control and links with the health and safety at workplaces and related surveillance systems, have to be considered as priorities. In the Italian context, the experiences of occupational diseases surveillance systems with individual assessment of exposure (such as mesothelioma regional registries) could represent a model to develop a systematic and nationally coordinated active search of COVID-19 cases including the anamnestic analysis of the circumstances in which the infection is acquired.

In conclusion, the Italian experience in monitoring and contrasting the COVID-19 epidemic demonstrates the significance of the occupational fraction of this disease, according to the compensation claim figures. The identification of economic sectors at risk of infection for workers appears coherent with insurance data. Finally, the need to go towards an epidemiological surveillance system with a comprehensive assessment of occupational risk factors in patients with COVID-19 has to be underlined.

Contributors AM and SI conceived and designed the study. FB, BMR, SDA and AB performed data collection and analysis. AM contributed in performing the statistical analysis and drafting the manuscript. SI, FB and BMR participated in interpreting the data and in revising the manuscript. All authors approved the final manuscript.

Funding The authors have not declared a specific grant for this research from any funding agency in the public, commercial or not-for-profit sectors.
Competing interests None declared.

Patient consent for publication Not required.

Provenance and peer review Not commissioned; externally peer reviewed.

Data availability statement No data are available. No additional data.

Open access This is an open access article distributed in accordance with the Creative Commons Attribution Non Commercial (CC BY-NC 4.0) license, which permits others to distribute, remix, adapt, build upon this work non-commercially, and license their derivative works on different terms, provided the original work is properly cited, appropriate credit is given, any changes made indicated, and the use is non-commercial. See: http://creativecommons.org/licenses/by-nc/4.0/.

\section{ORCID iDs}

Alessandro Marinaccio http://orcid.org/0000-0001-9068-2137

Fabio Boccuni http://orcid.org/0000-0002-4976-631X

Bruna Maria Rondinone http://orcid.org/0000-0002-4024-9877

Sergio lavicoli http://orcid.org/0000-0002-5956-9723

\section{REFERENCES}

1 Burdorf A, Porru F, Rugulies R. The COVID-19 (coronavirus) pandemic: consequences for occupational health. Scand J Work Environ Health 2020;46:229-30.

2 Sim MR. The COVID-19 pandemic: major risks to healthcare and other workers on the front line. Occup Environ Med 2020;77:281-2.

3 World Health Organization (WHO). Revised case report form for confirmed novel coronavirus COVID-19 (report to who within 48 hours of case identification). Available: https://apps.who.int/iris/bitstream/handle/10665/331234/WHO-2019nCoV-SurveillanceCRF-2020.2-eng.pdf

4 Italian Institute of Health (ISS). Sorveglianza integrata COVID-19: I principali dati nazionali. Available: https://www.epicentro.iss.it/coronavirus/sars-cov-2-sorveglianza-dati

5 Italian Workers' Compensation Authority (INAIL). Documento tecnico sulla possibile rimodulazione delle misure di contenimento del contagio dA SARS-Cov-2 Nei luoghi di lavoro E strategie di prevenzione, 2020. Available: https://www.inail.it/cs/internet/ 
comunicazione/pubblicazioni/catalogo-generale/pubbl-rimodulazione-contenimentocovid19-sicurezza-lavoro.html

6 Italian National Institute of Statistics (ISTAT). Memoria scritta dell'Istituto nazionale di statistica per la 5a Commissione programmazione economica e bilancio del Senato della Repubblica. Available: https://www.istat.it/it/files//2020/03/Aggiornamento_ MemoriaAS-1766_rev31marzo.pdf [Accessed 25 Mar 2020].

7 Italian National Institute of Statistics (ISTAT). Classificazione delle attivit economiche ATECO 2007 derivata dalla Nace Rev. 2. Metodi E Norme N. 40. Rome: ISTAT; 2009. Available: https://www.istat.it/it/files//2011/03/metenorme09_40classificazione_ attivita_economiche_2007.pdf
8 Us department of labor, employment and training administration, 2019. 0*NET 24.2 database. Available: https://www.onetcenter.org/dictionary/24.2/excel/ [Accessed 7 Jul 2020].

9 Dyal JW, Grant MP, Broadwater K, et al. COVID-19 Among Workers in Meat and Poultry Processing Facilities - 19 States, April 2020. MMWR Morb Mortal Wkly Rep 2020;69. doi:10.15585/mmwr.mm6918e3. [Epub ahead of print: 08 May 2020].

10 Akiyama MJ, Spaulding AC, Rich JD. Flattening the Curve for Incarcerated Populations - Covid-19 in Jails and Prisons. N Engl J Med 2020;382:2075-7.

11 Mosites E, Parker EM, Clarke KEN, et al. Assessment of SARS-CoV-2 Infection Prevalence in Homeless Shelters - Four U.S. Cities, March 27-April 15, 2020. MMWR Morb Mortal Wkly Rep 2020;69:521-2. 